the next most common lesion. In two patients histological examination showed that the polyps were malignant and a further nine patients had a carcinoma. The remaining patients had benign strictures ( 5 cases), diverticular disease (3), and miscellaneous diagnoses (3).

\section{Discussion}

Flexible sigmoidoscopy is a valuable initial investigation in patients with colonic symptoms and can be carried out on outpatients in a similar way to that practised widely for the examination of the upper gastrointestinal tract. Elaborate home or hospital preparation is not necessary, $82 \%$ of patients being well prepared after a single high-volume enema. In $53 \%$ of patients a lesion was found at the time of the examination. The series consisted, however, of selected patients, in some of whom a diagnosis of ulcerative colitis had already been established but the examination had been deemed necessary as part of their management. In 46 patients the proximal colon was easily visualised at this first examination and in this group subsequent barium enema was considered unnecessary.

An exact record of the time taken for each examination was not kept and will obviously vary among operators. Nevertheless, the procedure was thought to be comparable to upper gastrointestinal endoscopy and was usually terminated after 10-20 minutes unless a polyp or other lesion was found. We have always used premedication before flexible sigmoidoscopy and agree with Thompson et $a l^{3}$ that endoscopy under sedation is much less unpleasant for the patient.

Two previous studies of flexible sigmoidoscopy ${ }^{2}$ have used a $60-\mathrm{cm}$ instrument and have found lesions in $39 \%$ and $44 \%$ of patients. In these studies low-volume enemas were used in patients who were not sedated. In our study we used the standard long colonoscope for the examination and this allowed the colon beyond the sigmoid to be visualised in $78(68 \%)$ patients. In these patients little additional time was spent on the examination and a greater diagnostic yield was obtained. Short instruments offer little advantage over long instruments, which allow the operator greater freedom of movement at a more comfortable distance from the patient. We still use rigid sigmoidoscopy in some patients, particularly those young patients thought to be suffering from the irritable bowel syndrome on whom complete investigations have not been undertaken and patients with severe symptoms suggestive of ulcerative colitis on whom an immediate sigmoidoscopy is thought to be necessary. There were no complications from flexible sigmoidoscopy, which appears to be a valuable, well tolerated, and simple outpatient procedure for the management of suspected colonic disease.

\section{References}

${ }^{1}$ Bohlman TW, Katon RM, Lipshutz GR, McCool MF, Smith FW Melnyk CS. Fiberoptic pansigmoidoscopy : an evaluation and comparison with rigid sigmoidoscopy. Gastroenterology 1977;72:644-9.

2 Marks G, Whitney-Boggs H, Castro AF, Gathright JB, Ray JE, Salvati E. Sigmoidoscopic examinations with the rigid and flexible fiberoptic sigmoidoscopes in the surgeon's office: a comparative study of effectiveness in 1012 cases. Dis Colon Rectum 1979;22:162-8.

3 Thompson DG, Evans SJ, Murray RS, Lennard-Jones JE, Cowan RE, Wright JT. Patients appreciate premedication for endoscopy. Lancet $1980 ;$ ii :469-70.

(Accepted 12 August 1981)

\title{
Would a medium-nicotine, low-tar cigarette be less hazardous to health?
}

\author{
R STEPNEY
}

\begin{abstract}
Smoking behaviour and exposure to carbon monoxide, nicotine, and tar were studied in 19 middle-tar smokers. All smoked their own brands for three weeks and then switched to either a conventional low-nicotine, low-tar brand (control) or a medium-nicotine, low-tar cigarette for a further three weeks, the order then being reversed. The medium-nicotine, low-tar brand also had a low delivery of carbon monoxide.

With the medium-nicotine, low-tar cigarette mouthlevel delivery and intake of nicotine was similar to that with the smokers' usual brands, and significantly greater than with the control low-tar cigarette. Intake of carbon monoxide from the medium-nicotine, low-tar cigarette was significantly less than with either own or control brands. With both low-tar brands mouth-level exposure to tar was reduced relative to smokers' usual cigarettes. There was no evidence, however, that the reduction in tar exposure was greater with the medium-nicotine
\end{abstract}

University of Cambridge Clinical School, Department of Medicine, Addenbrooke's Hospital, Cambridge CB2 2QQ

R STEPNEY, MA, MSC, research psychologist brand than with the control low-tar cigarette. Both lowtar brands were "oversmoked" relative to subjects' usual middle-tar cigarettes.

The medium-nicotine, low-tar cigarette was marginally more acceptable than the control brand, and the particular design used in the study resulted in a lower intake of carbon monoxide. In terms of reducing mouthlevel exposure to tar, however, the medium-nicotine, low-tar cigarette had no advantage over the control lowtar product. In part this was because the ratio of tar to nicotine delivery obtained by human smokers was not the same as that obtained by smoking machine.

\section{Introduction}

Smokers unwilling to abstain have been encouraged to smoke cigarettes with low yields of tar. ${ }^{2}{ }^{2}$ Though almost all smokers have tried low-tar brands, however, only a few have switched permanently to them. (In 1977 only $12 \%$ of cigarettes sold in Britain were in the Government's low-tar category. ${ }^{3}$ ) Moreover, those smokers who have switched smoke more intensively, taking a greater volume of smoke (personal paper presented to a meeting on carbon monoxide and smoke intake, Southampton, March 1980) and inhaling more deeply. ${ }^{4}$ Any reduction in actual tar exposure is therefore likely to be considerably smaller than 
that anticipated from yields measured by smoking machines. ${ }^{5}$ The problems of limited acceptability and of "oversmoking" may arise because current low-tar cigarettes also have a low yield of nicotine. ${ }^{6}$

Smokers apparently seek a pharmacological dose of nicotine and adjust their smoking behaviour to achieve this. Many of the adverse effects of smoking, on the other hand, are caused not by nicotine but by tar. Hence a more realistic attempt to reduce the hazards of smoking might be to alter the ratio of tar to nicotine delivery and develop a low-tar cigarette yielding a moderate amount of nicotine. ${ }^{6-8}$ In view of the probable adverse effects of carbon monoxide, ${ }^{9}$ any low-tar, mediumnicotine cigarette should also have a low delivery of carbon monoxide. ${ }^{78}$ Commercial brands already show an increased delivery of nicotine per unit of tar, ${ }^{10}$ and probably there will soon be acceptable cigarettes with a much more "advantageous" ratio of tar to nicotine. We must therefore assess whether this approach is likely to be effective.

Three studies have used cigarettes of altered tar to nicotine ratio. ${ }^{11-13}$ No study examined more than one measure of smoke exposure, however, and two tested only a small number of smokers and the results were unclear. In the third and most recent study ${ }^{13}$ subjects took smaller puffs from a mediumnicotine, high-tar cigarette than from a low-nicotine, high-tar one, and the intake of carbon monoxide was also slightly less. This is consistent with the view that a moderate yield of nicotine might decrease exposure to other smoke constituents. The cigarettes were untipped, however, and of very high tar yield, and smokers rated them as unsatisfying irrespective of nicotine delivery. The general relevance of the findings was also restricted, as subjects were studied only when smoking their first cigarette of the day.

In this study 19 smokers of middle-tar brands were switched to a conventional low-tar, low-nicotine (control) cigarette and to a low-tar, medium-nicotine, low-carbon monoxide cigarette. I hoped that the medium-nicotine, low-tar cigarette would provide an adequate intake of nicotine without the need for oversmoking, and that exposure to tar and carbon monoxide would therefore be appreciably reduced. I also thought that the medium-nicotine, low-tar cigarette would prove more acceptable.

\section{Subjects and methods}

Subjects-Nineteen healthy volunteers (nine men and 10 women) with a mean age of 27 took part. All were regular, inhaling smokers of king-size, medium-tar, filter-tipped cigarettes. The mean consumption reported was $129+$ SD 57 cigarettes a week.

Cigarettes-Table I shows the standard nicotine, tar, and carbon monoxide deliveries of the subjects' own medium-tar brands and of the two low-tar cigarettes. "Total particulate matter" consists

TABLE I-Characteristics of cigarettes, as determined by smoking machine

\begin{tabular}{lccccc}
\hline & \multicolumn{4}{c}{ Standard delivery (mg) } & Tar to \\
\cline { 2 - 5 } & Nicotine & Tar & $\begin{array}{c}\text { Total } \\
\text { particulate } \\
\text { matter }\end{array}$ & $\begin{array}{c}\text { Carbon } \\
\text { monoxide } \\
\text { ratio }\end{array}$ \\
\hline $\begin{array}{l}\text { Own medium-tar } \\
\text { brands (mean) }\end{array}$ & 1.55 & 19 & 22 & 18 & 12 \\
$\begin{array}{c}\text { Control low-tar } \\
\text { Medium-nicotine, } \\
\text { low-tar }\end{array}$ & 0.7 & 11 & 13 & 13 & 16 \\
\hline
\end{tabular}

predominantly of tar but also includes nicotine and water. All deliveries were measured using UK Government Chemist machine-smoking criteria. The medium-nicotine, low-tar cigarette yielded $70 \%$ of the nicotine delivered by the subjects' usual brands, and the control lowtar cigarette $45 \%$. The two brands were virtually identical in tar yield, but their tar to nicotine ratios were widely different. The delivery of carbon monoxide of the medium-nicotine, low-tar cigarette was one-third that of the smokers' own brands and under half that of the control cigarette. The enhanced delivery of the mediumnicotine brand was achieved by design of the cigarette and not by adding nicotine. Both brands were king-size and of the same tip length and appearance.

Procedure-After an initial laboratory attendance for familiarisation, subjects smoked their own brands for three weeks, coming to the laboratory at weekly intervals. They were then divided into two matched groups, one smoking the control cigarette for three weeks before being switched to the medium-nicotine, low-tar brand, the other smoking the brands in the reverse order.

Smoking behaviour-Each subject recorded the number of cigarettes smoked. At each laboratory attendance subjects smoked a single cigarette through a small holder enabling draw pressure and the flow of smoke to be measured and recorded.14 Numbers of puffs, time taken to smoke the cigarette, and total smoke volume were calculated. Subjects collected butts from all cigarettes smoked in the 24 hours before the attendance, and these and the laboratory butts were measured, and filters assayed for nicotine.

Carbon monoxide intake - A sample of exhaled air was obtained immediately before and after each laboratory cigarette was smoked. Subjects inhaled, held their breath for 20 seconds, and exhaled. The first $500 \mathrm{ml}$ of exhalate was discarded, and the concentration of carbon monoxide in the remainder measured using an Ecolyzer monitor. The rise in concentration provides a measure of carbon monoxide intake from a single cigarette, while the presmoking concentration reflects intake from a longer period of smoking outside the laboratory. Longterm exposure to carbon monoxide correlates highly with exposure to nicotine (as reflected by plasma concentrations), and carbon monoxide intake is a reliable guide to relative exposure to nicotine in a population smoking cigarettes of different design. ${ }^{15}$

Urine nicotine and cotinine-Subjects made a full 24-hour collection of urine before each attendance. An aliquot was assayed for nicotine and cotinine concentrations using a gas-liquid chromatographic method based on that of Feyerabend and Russell. ${ }^{16}$

Mouth-level exposure to nicotine and tar-The amount of nicotine and tar retained by a filter is proportional to the amount which passes through. Hence if the efficiency of the filter is known the delivery of tar and nicotine to the smoker's mouth may be estimated. Efficiency of filtration is usually established by machines smoking cigarettes to standardised criteria. Since the retention of tar and nicotine depends on the way the cigarette is smoked, ${ }^{14}{ }^{17}$ however, the efficiencies of filtration obtained by human smokers vary from one smoker to another and differ from those obtained by standard machine-smoking. This problem was overcome by using a smoking machine to duplicate the exact pattern of puffing employed by a human smoker. In this way smoking patterns were reproduced for each subject and cigarette type, providing data on the actual mouth-level deliveries of nicotine and total particulate matter and on the relation between deliveries and the amount of nicotine retained by the tip. These data enabled deliveries to be estimated for cigarettes smoked outside the laboratory. Mouthlevel deliveries represent the maximum amount of a constituent of smoke available for inhalation and not necessarily the amount actually taken into the lungs or the amount retained in the body. Nevertheless, estimating mouth-level delivery, especially when attempting to estimate tar exposure, is the most direct measure available.

Cigarette acceptability-Subjects' impressions of the two low-tar brands were investigated using $100 \mathrm{~mm}$ bipolar rating scales.

Analysis of results-Data were analysed to determine whether there were reliable differences between the medium-nicotine, liw-tar cigarette and the control low-tar brand. Each of the low-tar brands was also compared with the smokers' usual medium-tar cigarettes. Since three sets of data were available, a mean value was calculated for each smoker using each brand. Comparisons were made using Student's matched-pairs $t$-test (two-tailed).

\section{Results}

Smoking behaviour (table II)-There were no reliable differences in daily consumption of cigarettes among the three brands or in the lengths of butts left after smoking the laboratory cigarettes. Subjects in their usual environment, however, smoked the control low-tar cigarette to a shorter butt than the medium-nicotine cigarettes. In the laboratory, subjects smoked the control low-tar cigarette more quickly than the medium-nicotine, low-tar brand but did not take more puffs or receive a greater volume of smoke. Subjects took a greater volume of smoke from both low-tar cigarettes than from their own brands.

Carbon monoxide intake (table III) was less with the control low-tar 
TABLE II-Mean values for smoking behaviour, according to brand

\begin{tabular}{|c|c|c|c|c|c|c|c|c|c|c|c|}
\hline & & & & & & \multirow{2}{*}{$\begin{array}{c}\text { No smoked } \\
\text { daily }\end{array}$} & \multicolumn{2}{|c|}{ Butt length (mm) } & \multirow{2}{*}{$\begin{array}{l}\text { Time to smoke } \\
\text { cigarette }(s)\end{array}$} & \multirow{2}{*}{$\begin{array}{l}\text { No of } \\
\text { puffs }\end{array}$} & \multirow{2}{*}{$\begin{array}{l}\text { Total smoke } \\
\text { volume (ml) }\end{array}$} \\
\hline & & & & & & & Laboratory & $\begin{array}{l}24 \text { Hours before } \\
\text { attendance }\end{array}$ & & & \\
\hline \multicolumn{3}{|c|}{$\begin{array}{l}\text { Own medium-tar brands (1) } \\
\text { Control low-tar (2) } \quad \therefore \\
\text { Medium-nicotine, low-tar (3) }\end{array}$} & $\begin{array}{l}\cdots \\
\cdots\end{array}$ & $\begin{array}{l}\cdots \\
\cdots\end{array}$ & $\begin{array}{l}\cdots \\
\cdots\end{array}$ & $\begin{array}{l}18 \cdot 1 \\
19 \cdot 1 \\
18 \cdot 9\end{array}$ & $\begin{array}{l}33 \cdot 4 \\
32 \cdot 3 \\
33 \cdot 4\end{array}$ & $\begin{array}{l}33 \cdot 1 \\
30 \cdot 7 \\
32 \cdot 2\end{array}$ & $\begin{array}{l}400 \\
361 \\
394\end{array}$ & $\begin{array}{l}12 \cdot 9 \\
11 \cdot 9 \\
12 \cdot 3\end{array}$ & $\begin{array}{l}485 \\
540 \\
560\end{array}$ \\
\hline $\begin{array}{l}\text { p Values: } \\
\text { (1) } v(2) \ldots \\
\text { (2) } v(3) \ldots \\
\text { (1) } v(3) \ldots\end{array}$ & $\begin{array}{l}\cdots \\
\cdots\end{array}$ & $\begin{array}{l}\cdots \\
\cdots\end{array}$ & $\begin{array}{l}\cdots \\
\cdots\end{array}$ & $\begin{array}{l}\cdots \\
\cdots\end{array}$ & $\begin{array}{l}\cdots \\
\cdots\end{array}$ & $\begin{array}{l}\text { NS } \\
\text { NS }\end{array}$ & $\begin{array}{l}<0 \cdot 1 \\
\text { NS }\end{array}$ & $\begin{array}{l}<0.001 \\
<0.01 \\
<0.1\end{array}$ & $\begin{array}{l}<0.001 \\
<0.01 \\
\text { NS }\end{array}$ & $\begin{array}{l}<0.05 \\
\text { NS } \\
\text { NS }\end{array}$ & $\begin{array}{l}<0.05 \\
\text { NS } \\
<0.01\end{array}$ \\
\hline
\end{tabular}

NS = Not significant.

TABLE III-Mean exposure to carbon monoxide, nicotine, and tar (total particulate matter) according to brand

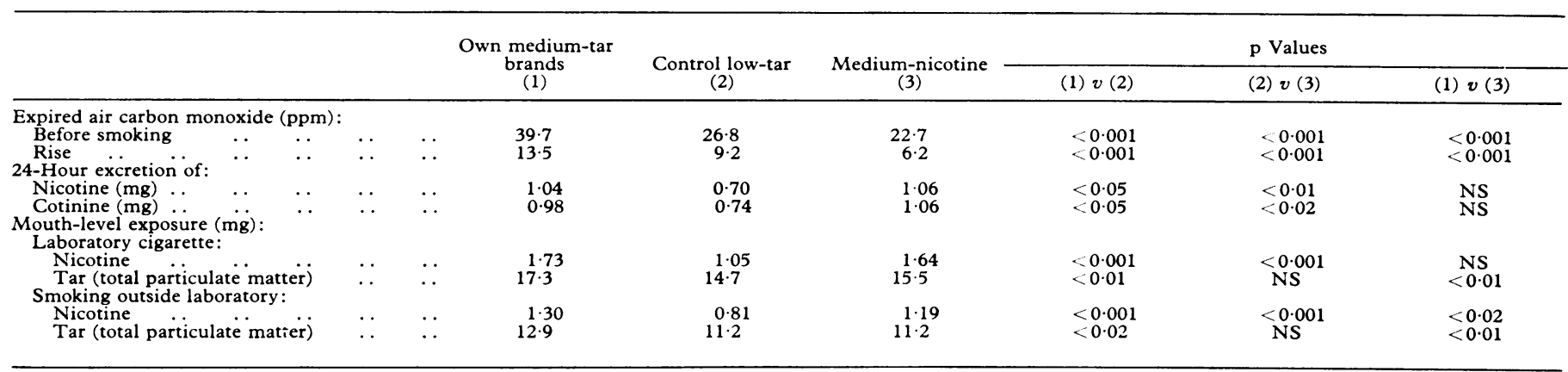

NS = Not significant.

cigarette than from the subjects' own brands, and less from the medium-nicotine cigarette than with the control brand $(p<0.001)$. Intake of carbon monoxide from the control cigarette was roughly that expected on the basis of standard yield; the standard delivery was $28 \%$ less than with the smokers' own brands, and the observed intake was $32 \%$ less. Intake of carbon monoxide from the medium-nicotine, low-tar cigarette, however, was greater than expected; though the standard yield was $67 \%$ less, the observed intake indicated by presmoking concentrations was only $43 \%$ less, and the intake from the laboratory-smoked cigarette only $54 \%$ less. Figures 1 and 2 show this proportionately greater carbon monoxide intake from the mediumnicotine, low-tar cigarette.

Urine nicotine and cotinine-Twenty-four-hour urinary excretions of nicotine and cotinine were closely similar when subjects were

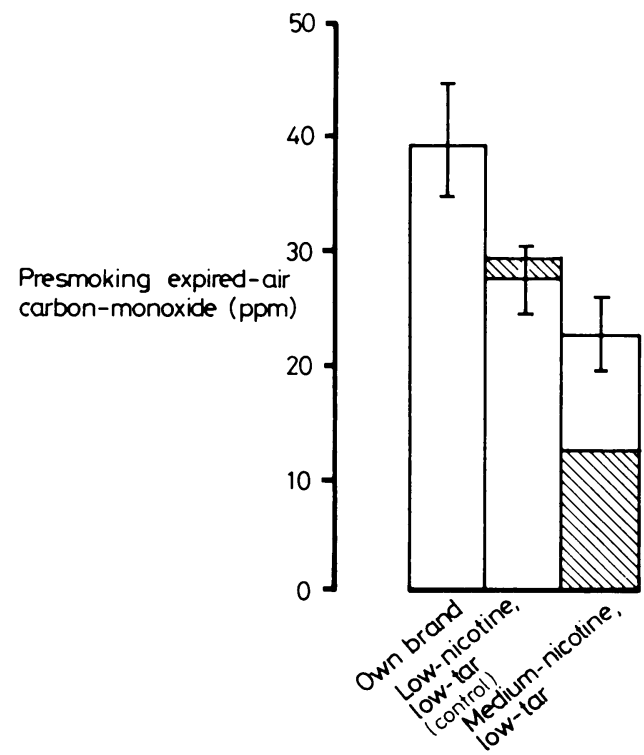

FIG 1-Expired-air carbon monoxide (ppm) before smoking. Hatched area represents result expected if subjects had smoked low-tar cigarettes in same way as their own brands. Values are means \pm SEM.

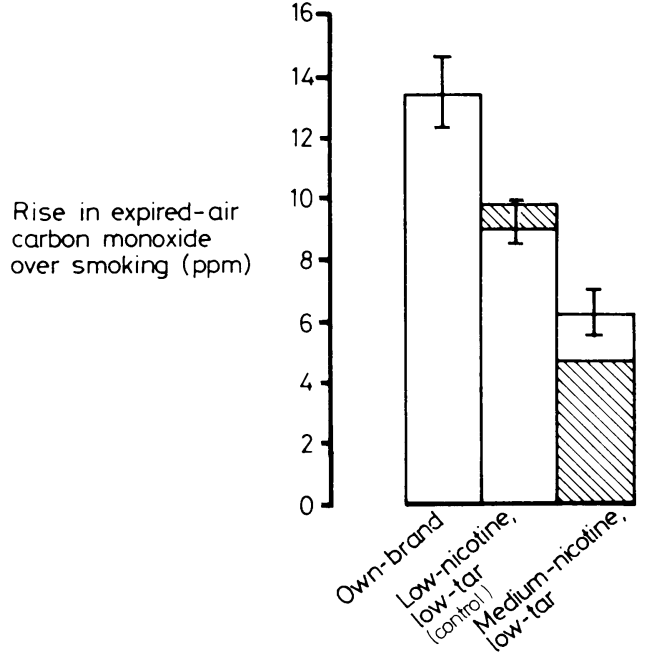

FIG 2-Rise in expired-air carbon monoxide (ppm) over smoking. Hatched area represents rise expected if subjects had smoked low-tar cigarettes in same way as their own brands. Values are means \pm SEM.

smoking their own brands and the medium-nicotine, low-tar cigarette (table III ; fig 3). With the control low-tar cigarette, however, excretion was significantly less. Proportionately more nicotine and cotinine was excreted with both the control and medium-nicotine, low-tar cigarettes than with own brands, and the differences between observed and expected values were similar.

Mouth-level exposure to nicotine and tar-The mouth-level delivery of nicotine was significantly greater with the medium-nicotine, lowtar cigarette than with the control low-tar brand (table III). The nicotine delivered from own brands was also significantly greater. Differences in nicotine delivery between own brands and the mediumnicotine, low-tar cigarette were small. Figure 4 shows that the actual mouth-level nicotine delivery from both the control and mediumnicotine, low-tar brands was greater than expected, relative to own brands and relative to standard delivery. The difference between expected and actual delivery was similar with both low-tar brands. With both low-tar cigarettes mouth-level delivery of total particulate matter was significantly less than with the smokers' usual brands. The 
tar exposure from both low-tar cigarettes was, however, greater than would have occurred had the low-tar brands been smoked in the same way as the usual medium-tar cigarettes. There was no significant difference in exposure to total particulate matter between lownicotine and medium-nicotine, low-tar brands, and no suggestion that the difference between expected and observed deliveries was greater for the control than for the medium-nicotine cigarette (fig 5).

Acceptability-Subjects rated the medium-nicotine, low-tar cigarette as slightly more satisfying than the control low-tar brand (table IV), but neither low-tar cigarette was rated as unsatisfying. The medium-nicotine, low-tar cigarette was not perceived as stronger than the control brand, though it was rated as providing more "tobacco taste."

Tar to nicotine ratios-Though the standard machine-smoked

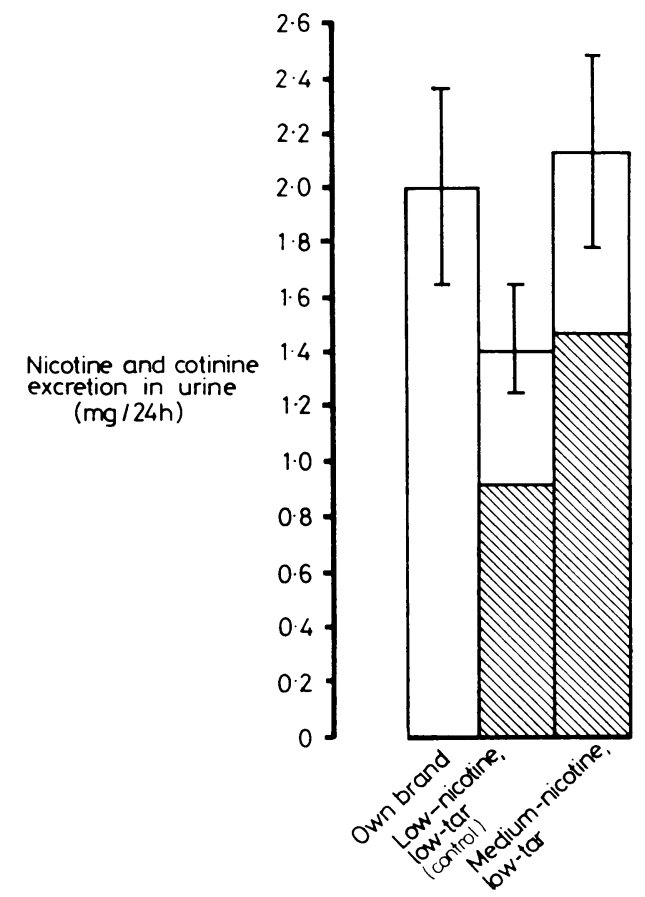

FIG 3-Twenty-four-hour excretion of nicotine and cotinine in urine (mg). Hatched area represents excretion expected if subjects had smoked low-tar cigarettes in same way as their own brands. Values are means $\pm S E M$.

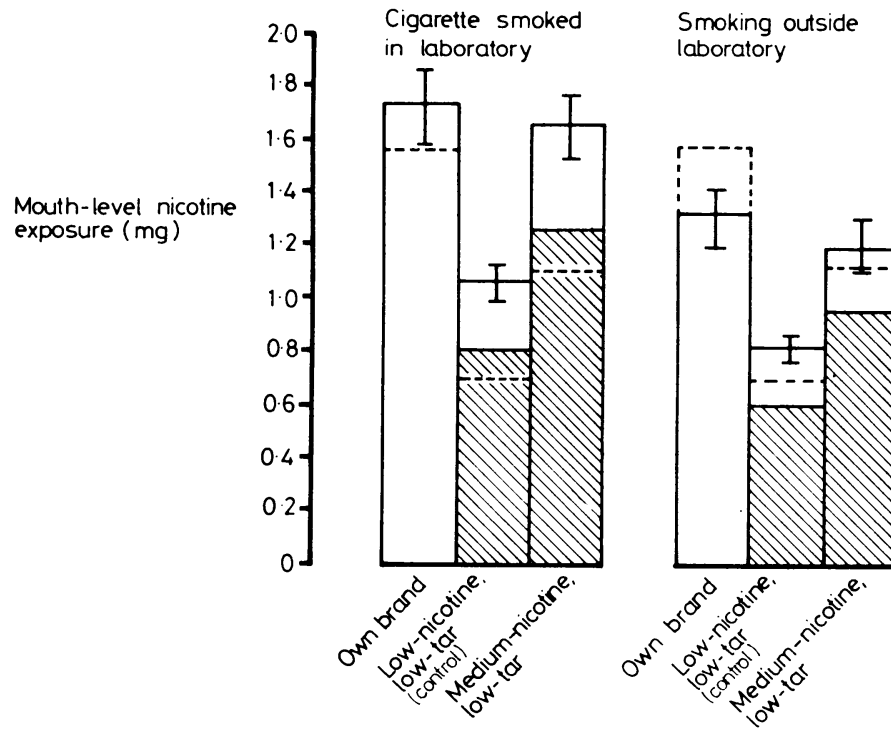

FIG 4-Mouth-level nicotine exposure (mg) from cigarette smoked in laboratory, and average exposure from cigarettes smoked over preceding 24 hours. Hatched areas represent exposure expected if subjects had smoked low-tar cigarettes in same way as their own brands. Dashed lines show machine-smoked standard nicotine yields. Values are means $\pm S E M$.

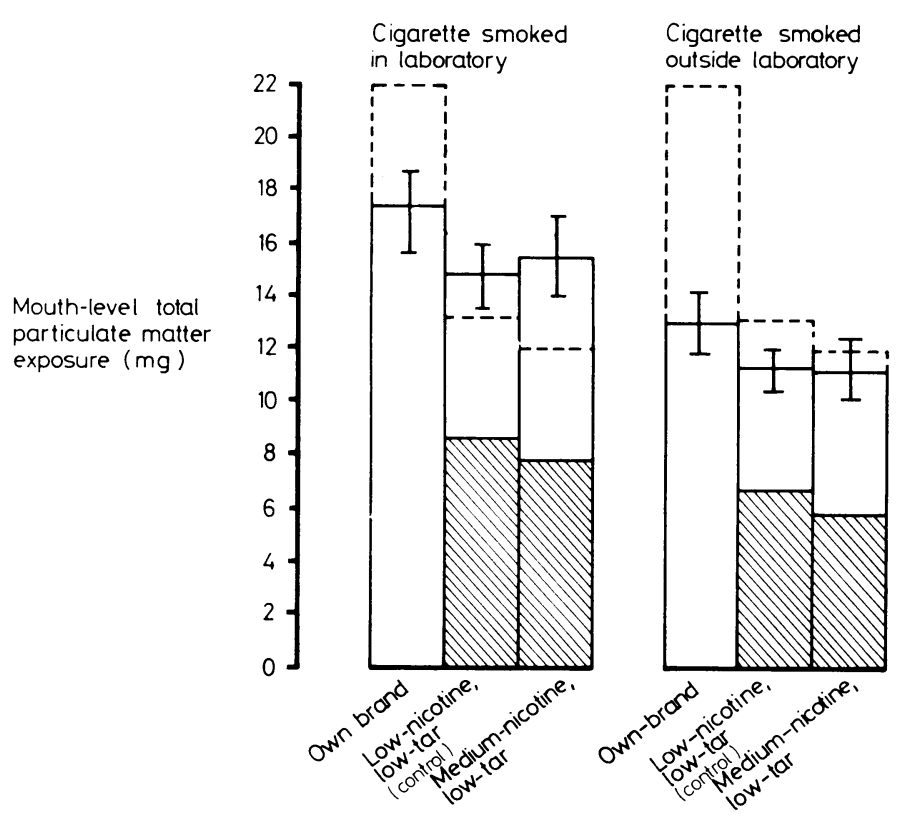

FIG 5-Mouth-level exposure to total particulate matter (mg) from cigarette smoked in laboratory and average exposure from cigarettes smoked over preceding 24 hours. Hatched areas show exposure expected if subjects had smoked low-tar cigarettes in same way as they smoked their own brands. Dashed lines show machine-smoked yields of total particulate matter. Values are means $\pm S E M$.

TABLE IV-Cigarette acceptability (100 $\mathrm{mm}$ bipolar rating scales)

\begin{tabular}{lcccc}
\hline & $\begin{array}{c}\text { Satisfaction } \\
(100=\text { very } \\
\text { satisfying })\end{array}$ & $\begin{array}{c}\text { Difficulty } \\
\text { keeping to } \\
\text { cigarette } \\
(100=\text { very } \\
\text { difficult })\end{array}$ & $\begin{array}{c}\text { Strength } \\
(100=\text { much } \\
\text { too weak })\end{array}$ & $\begin{array}{c}\text { Taste } \\
\left(\begin{array}{c}100=\text { a lot } \\
\text { of taste })\end{array}\right.\end{array}$ \\
\hline Control low-tar & 42 & 26 & 39 & 29 \\
Medium-nicotine, low-tar & 47 & 18 & 33 & 42 \\
\hline $\mathrm{p}$ & $<0.1$ & $<0.05$ & NS & $<0.02$ \\
\hline
\end{tabular}

NS $=$ Not significant

deliveries of the three types of cigarette showed widely differing tar to nicotine ratios, the ratios actually obtained by the human smokers were similar (table V). Smokers obtained a greater delivery of nicotine per unit of tar (relative to standardised machine smoking) from all three brands. This "improvement" was greater with subjects' own brands and with the control low-tar cigarette, which had relatively "poor" machine-smoked ratios, than with the medium-nicotine, lowtar cigarette, which already had an advantageous ratio.

TABLE V-Tar (total particulate matter) to nicotine ratios of standardised machine-smoked deliveries and those obtained by human smokers

\begin{tabular}{lccc}
\hline & $\begin{array}{c}\text { Own medium-tar } \\
\text { brands }\end{array}$ & $\begin{array}{c}\text { Control } \\
\text { low-tar }\end{array}$ & $\begin{array}{c}\text { Medium-nicotine } \\
\text { low-tar }\end{array}$ \\
\hline Machine smoking & $14 \cdot 2$ & 18.6 & $10 \cdot 9$ \\
Human smoking & 10.0 & 14.0 & 9.5
\end{tabular}

\section{Discussion}

These results were surprising in that response to the mediumnicotine, low-tar cigarette generally did not differ in the expected way from response to the low-nicotine, low-tar (control) brand. The medium-nicotine cigarette was marginally more acceptable, and subjects left a longer butt. Measurement of total smoke volume, however, showed that medium-tar smokers oversmoked both low-tar brands (relative to their usual cigarettes) to a 
similar extent. This complements evidence from measures of smoke exposure. Analysis of nicotine and cotinine in urine and estimation of mouth-level delivery suggested that smokers obtained proportionately more nicotine and tar from the low-tar brands than from their usual cigarettes. Moreover, apparent compensation for reduced standard delivery seemed to have been just as great with the medium-nicotine, low-tar cigarette as with the control low-tar brand. Carbon monoxide intake was greater than expected with the medium-nicotine, low-tar cigarette but not with the control brand.

Though the intake of carbon monoxide from the mediumnicotine brand exceeded that expected on the basis of the standard yield, actual carbon monoxide exposure was still reduced significantly relative both to own brands and to the control low-tar cigarette. In this respect the particular design of the medium-nicotine, low-tar cigarette used might be less hazardous. Nevertheless, my results question the benefit of low-tar, medium-nicotine cigarettes. Firstly, smokers of medium-tar cigarettes were apparently not content with the $1.1 \mathrm{mg}$ of nicotine "available" from the medium-nicotine, lowtar cigarette. Instead, they smoked in such a way as to raise the nicotine delivery to that of their usual brands. Their exposure to tar was therefore greater than expected and not reduced relative to the control cigarette. Secondly, smokers smoke cigarettes of poor tar to nicotine ratio in such a way that the delivery of nicotine is increased relative to that of tar. With cigarettes that have already been designed to give an advantageous machine ratio, however, any improvement that the smoker may make is slight. Thus extrapolating from the tar to nicotine ratios of machine smoking to those obtained by human smokers may be as difficult as extrapolation of absolute deliveries. ${ }^{518}$

The amount of tar obtained by the subjects did not differ greatly with the brands. Probably not surprisingly the actual delivery of tar was similar for the two low-tar brands, which had similar machine-smoked deliveries, but the absence of a major difference between the tar delivery of medium-tar and low-tar brands requires comment. For whatever reason, the pattern of smoking used by the smokers reduced differences in tar delivery more effectively than it compensated for differences in standard nicotine yield. It would go against a considerable body of evidence to suggest that smokers alter their behaviour to obtain a constant intake of tar. Nevertheless, that subjects responded in much the same way to low-tar cigarettes of different tar to nicotine ratio but similar tar yield requires explanation. Conceivably smokers use the sensory cues obtained from the taste and irritation of a given amount of tar as a guide to the amount of nicotine they are receiving. Since the tar and nicotine yields of commercially available cigarettes are closely correlated, ${ }^{6}$ this would be an appropriate strategy and one that smokers might take time to unlearn. The amount of smoke taken from a cigarette might also be affected by a complex interaction between the sensory impact of tar and nicotine. ${ }^{19}$

The role of sensory factors in smoking has never been properly elucidated. It would be difficult to design an experiment to distinguish between the peripheral sensory effects of smoke and the central pharmacological actions of nicotine, and possibly the question could be satisfactorily answered only if smoke intake from cigarettes of differing nicotine delivery were studied in smokers whose oral cavity had been anaesthetised (G Read and M Raw, personal communications). Whatever the difficulties, such an investigation might prove worth while, since my findings suggest that the response of smokers cannot be predicted on the basis of nicotine delivery alone.

I acknowledge the financial support of the British American Tobacco Co Ltd and the technical help of their group research and development centre, without which this study would not have been possible.

\section{References}

${ }^{1}$ Health Departments of the UK. Tar and Nicotine Yields of Cigarettes. London: DHSS, 1973-81.
2 Royal College of Physicians. Smoking or health. London: Pitman Medical, 1977.

${ }^{3}$ Capell PJ. Trends in cigarette smoking in the United Kingdom. Health Trends 1978;10:49-54.

4 Wald NJ, Idle M, Boreham J, Bailey A. Inhaling habits among smokers of different types of cigarette. Thorax $1980 ; 35: 925-8$.

${ }^{5}$ Russell MAH, Jarvis M, Iyer R, Feyerabend C. Relation of nicotine yield of cigarettes to blood nicotine concentrations in smokers. $\mathrm{Br} \mathrm{MedF}$ $1980 ; 280: 972-6$.

${ }^{6}$ Russell MAH. Low-tar medium-nicotine cigarettes: a new approach to safer smoking. $\mathrm{Br} \mathrm{Med} \mathcal{F} 1976$;i:1430-3.

Russell MAH. Realistic goals for smoking and health. Lancet 1974 ;i:254-8.

${ }^{8}$ Russell MAH. The case for medium-nicotine, low-tar, low-carbon monoxide cigarettes. In: Gori GB, Bock FG, eds. Banbury Report 3: a safe cigarette? New York: Cold Spring Harbor Laboratory, 1980: 297-310.

${ }^{9}$ Greenhalgh RM, ed. Smoking and arterial disease. London: Pitman Medical, 1981.

10 Stepney R. Tar:nicotine ratio of cigarettes (1973-1979). Lancet 1979;ii: 422-3.

${ }^{11}$ Goldfarb T, Gritz ER, Jarvik ME, Stolerman IP. Reactions to cigarettes as a function of nicotine and "tar." Clin Pharmacol Ther 1976;19:767-72.

12 Dunn PJ, Freiesleben ER. The effects of nicotine-enhanced cigarettes on human smoking parameters and alveolar carbon-monoxide levels. In: Thornton RE, ed. Smoking behaviour: physiological and psychological influences. Edinburgh: Churchill Livingstone, 1978:195-202.

13 Herning RI, Jones RT, Bachman J, Mines AH. Puff volume increases when low-nicotine cigarettes are smoked. Br Med f 1981 ;283 :187-9.

14 Creighton DE, Noble MJ, Whewell RT. Instruments to measure, record and duplicate human smoking patterns. In: Thornton RE, ed. Smoking behaviour: physiological and psychological influences. Edinburgh: Churchill Livingstone, 1978:277-88.

${ }^{15}$ Ashton H, Stepney R, Thompson JW. Should intake of carbon monoxide be used as a guide to intake of other smoke constituents ? $\mathrm{Br} \mathrm{Med} \mathcal{F}$ $1981 ; 282: 10-3$.

${ }^{16}$ Feyerabend C, Russell MAH. Improved gas-chromatographic method and micro-extraction technique for the measurement of nicotine in biological fluids. F Pharm Pharmacol 1979;31:73-6.

17 Creighton DE, Lewis PH. The effect of smoking pattern on smoke deliveries. In: Thornton RE, ed. Smoking behaviour: physiological and psychological influences. Edinburgh: Churchill Livingstone, 1978:301-14.

18 Ashton H, Stepney R, Thompson JW. Self-titration by cigarette smokers. Br Med F 1979;ii:357-60.

${ }^{19}$ Cain WS. Sensory attributes of cigarette smoking. In: Gori GB, Bock FG, eds. Banbury Report 3: a safe cigarette? New York: Cold Spring Harbor Laboratory, $1980: 239-49$.

(Accepted 28 August 1981)

COMMON MUGWORT hath divers leaves lying upon the ground, very much divided, or cut deeply in about the brims, somewhat like Wormwood, but much larger, of a dark green colour on the upper side, and very hoary white underneath. The stalks rise to be four or five feet high, having on it such like leaves as those below, but somewhat smaller, branching forth very much towards the top, whereon are set very small, pale, yellowish flowers like buttons, which fall away, and after them come small seeds inclosed in round heads. The root is long and hard, with many small fibres growing from it, whereby it takes strong hold on the ground; but both stalks and leaves do lie down every year, and the root shoots anew in the Spring. The whole plant is of a reasonable scent, and is more easily propagated by the slips than the seed.

It grows plentifully in many places of this land, by the water-sides; as also by small water courses, and in divers other places. It flowers and seeds in the end of Summer. This is an herb of Venus, therefore maintains the parts of the body she rules, remedies the diseases of the parts that are under her signs, Taurus and Libra. Mugwort is with good success put among other herbs that are boiled for women to apply the hot decoction to draw down their courses, to help the delivery of the birth, and expel the after-birth. As also for the obstructions and inflammations of the mother. It breaks the stone, and opens the urinary passages where they are stopped. The juice thereof made up with Myrrh, and put under as a pessary, works the same effects, and so does the root also. Being made up with hog's grease into an ointment, it takes away wens and hard knots and kernels that grow about the neck and throat, and eases the pains about the neck more effectually, if some Field Daisies be put with it. The herb itself being fresh, or the juice thereof taken, is a special remedy upon the overmuch taking of opium. Three drams of the powder of the dried leaves taken in wine, is a speedy and the best certain help for the sciatica. A decoction thereof made with Camomile and Agrimony, and the place bathed therewith while it is warm, takes away the pains of the sinews, and the cramp. (Nicholas Culpeper (1616-54) The Complete Herbal, 1850.) 